\title{
Em modo de espera: a condição de trabalho e vida uberizada
}

\author{
Nívea Maria Santos Souto Maior ${ }^{1}$ \\ https://orcid.org/0000-0003-4561-8819
}

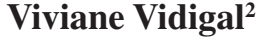 \\ https://orcid.org/0000-0003-2376-2916
}

${ }^{1}$ Universidade Federal de Pernambuco, Programa de Pós-Graduação em Direito, Recife, PE, Brasil

${ }^{2}$ Universidade Estadual de Campinas, Instituto de Filosofia e Ciências Humanas, Departamento de Sociologia, Programa de Pós-Graduação em Sociologia, Campinas, SP, Brasil

\section{Em modo de espera: a condição de trabalho e vida uberizada}

Resumo: O presente estudo tem como escopo compreender as condições do trabalho uberizado. Este novo modelo de exploração capitalista tem intrínseca relação com as novas tecnologias da informação e comunicação, de forma a intensificar e elastecer a jornada de trabalho. A hipótese sustentada é a de que esses trabalhadores estão em modo de espera, problematizando-se em dois eixos analíticos, a espera pelos chamados e a espera pelo reconhecimento de seus direitos. Para construir os argumentos, sob uma perspectiva metodológica crítico-dialética, serão apresentados dados empíricos, recolhidos de pesquisas qualitativas, desenvolvidas a partir da observação direta, da análise de documentos e da realização de entrevistas semiestruturadas com trabalhadores(as) de plataformas digitais da região metropolitana de Campinas-SP e São Paulo-SP. As entrevistas realizadas articuladas à bibliografia sobre o tema esmiuçarão argumentos que visam compreender como o estado do modo de em espera é internalizado pelos trabalhadores uberizados e as consequências na saúde.

Palavras-Chave: Uberização; Trabalho; Espera; Jornada; Direitos.

\section{In standby mode: the uberized life and labor condition}

Abstract: This paper aims to understand the conditions of uberized work. This new model of capitalist exploitation has an intrinsic relationship with the new information and communication technologies, in order to intensify and lengthen the working day. The hypothesis supported is that these workers are in a standby mode, problematizing in two analytical axes, waiting for calls and waiting for the recognition of their rights. To build the arguments, under a critical-dialectical methodological perspective, empirical data will be presented, collected from qualitative research, developed from direct observation, document analysis and semi-structured interviews with workers from digital platforms in the metropolitan area of Campinas-SP and São Paulo-SP. The interviews carried out in conjunction with the bibliography on the subject will scrutinize arguments that aim to understand how the state of the standby mode is internalized by uberized workers and the consequences on health.

Key Words: Uberization; Labor; Standby; Journey; Rights.

Recebido em: 30.06.2021. Aprovado em: 31.08.2021. Revisado em: 14.09.2021. 


\section{Introdução}

A arte imita a vida ou a vida imita a arte $?^{1}$ Este questionamento é oportuno às cenas de dois filmes, ambos dirigidos pelo britânico Ken Loach, no qual retratam a contemporânea condição de trabalho e vida do proletariado. No filme Eu, Daniel Blake (EU..., 2016), o amigo do personagem principal relata que, naquele dia, havia ficado muitas horas à disposição da empresa, mas que, no entanto, só havia trabalhado efetivamente 45 minutos descarregando um caminhão. Mais recentemente, o filme Você não estava aqui (VOCÊ..., 2019) relata a exaustiva rotina de um trabalhador uberizado que possuía uma jornada diária de 14 horas, sem tempo sequer para ir ao banheiro e de estar com sua família. Revelando um modo de vida quase análogo à escravidão que, traz consequências não apenas ao trabalhador, mas também sua família, como o sofrimento dos filhos que ficam à espera desse pai. Estes longas-metragens britânicos são fiéis à realidade dos uberizados, que se encontram em situação de maior flagelo em países de capitalismo periférico como o Brasil.

$\mathrm{Na}$ realidade de nosso país, o trabalho uberizado ${ }^{2}$ se espraiou rapidamente em diversas atividades ${ }^{3}$. $\mathrm{Na}$ concretude brasileira, há diversos relatos sobre o dia-a-dia do trabalho uberizado. Uma notícia do jornal A Folha de São Paulo (MACHADO, 2017), datada de 09 de fevereiro de 2017, narrava o trabalho dos motoristas Uber, no Aeroporto Internacional de Guarulhos (GRU) onde eles esperavam por até 12 horas por uma única corrida diária. Naquele local de trabalho, centenas de carros ficavam parados em três bolsões próximos ao aeroporto: um terreno atrás de um hotel, nas ruas de um bairro de Guarulhos com prédios populares e no estacionamento de um hospital público. Enquanto aguardavam o chamado, mais de 200 motoristas tentavam a sorte todos os dias à míngua de condições básicas de trabalho, a comida era obtida em barracas improvisadas por ambulantes, usavam um banheiro químico por $\mathrm{R} \$ 1,50$ e retiravam a água de uma bica de um matagal próximo. Para serem chamados por um passageiro, tinham que esperar sua vez. A longa espera podia compensar ou não; podiam pegar rotas para o interior do Estado ou para cidades da Grande São Paulo, rotas em que seria possível ganhar mais de $\mathrm{R} \$ 100,00$ livres. Ao revés, o motorista poderia aguardar horas e, quando finalmente fosse chamado, pegar uma corrida de pouco valor, a exemplo, do centro de São Paulo que era um destino pouco lucrativo - em torno de $\mathrm{R} \$ 35,00$ (MACHADO, 2017).

$\mathrm{O}$ modo uberizado de organizar e remunerar a força de trabalho distancia-se da regularidade do assalariamento formal, acompanhado geralmente pela garantia dos direitos sociais e trabalhistas. Isso porque a empresa, que se considera parceira do trabalhador ao auxiliar a relação de oferta e demanda entre aquele e o usuário, além de não estabelecer qualquer vínculo empregatício formal, impõe longas e imprevisíveis jornadas de trabalho para que o trabalhador consiga auferir uma remuneração mínima que garanta sua subsistência. No caso em tela, não há garantia alguma: inexiste pagamento mínimo, a contribuição com o sistema de proteção social é individualizada e incerta, a despeito das extensas jornadas não há pagamento de horas-extras, nem descanso semanal remunerado, férias, ou seu respectivo terço legal. Trata-se de uma situação de instabilidade (VIDIGAL, 2020).

A hipótese sustentada neste artigo é a de que esses trabalhadores estão em modo de espera, problematizandose em dois eixos analíticos, a espera pelos chamados, cujo eixo central da crítica é o tempo de trabalho não pago e a espera pelo reconhecimento de seus direitos. Portanto, a condição de trabalho e vida uberizada é de espera. Questiona-se o que significa esperar, quando o que se está sem jogo é a sobrevivência.

As reflexões apresentadas são norteadas pelo pensamento crítico-dialético e terão como base uma análise qualitativa, onde os dados empíricos são fruto da pesquisa intitulada "As ilusões da uberização: um estudo à luz da experiência de motoristas Uber" (CASTRO, 2020), que fora realizada entre março de 2017 e dezembro de 2019, desenvolvida a partir da observação direta, da análise de documentos e contou com entrevistas semiestruturadas de 22 pessoas: 19 homens e três mulheres, motoristas de Uber- $\mathrm{X}^{4}$ nas cidades de Campinas (SP) e São Paulo (SP). Para este artigo, transcreve-se excertos das referidas entrevistas. Os nomes apresentados são fictícios e seguem o acordo de anonimato firmado entre entrevistados(as) e a pesquisadora. As entrevistas realizadas articuladas à bibliografia sobre o tema esmiuçarão argumentos que visam compreender como o estado do modo em espera é internalizado pelos trabalhadores uberizados e as consequências na saúde.

O estudo está estruturado, para além da introdução, nas seguintes seções: primeiramente, o texto debate sobre a jornada de trabalho dos uberizados, em destaque o tempo de prontidão, à espera de chamados, enquanto horas de trabalho não pagas. Em sequência, o estudo abordará a ausência de direitos trabalhistas e sociais na uberização do trabalho, evidenciado pelo não reconhecimento do vínculo empregatício com as plataformas 
digitais. Na terceira seção, a saúde destes trabalhadores será problematizada, evidenciando o sofrimento psíquico na contínua espera dos chamados de trabalho remunerado e por melhores condições de trabalho e de vida. A última parte estabelece aproximações conclusivas de modo a verificar a exclusão de direitos e a desproteção sobre os limites da jornada no trabalho uberizado, à mercê do despotismo da plataforma/aplicativos.

\section{Tempo em espera: a jornada invisibilizada e não paga}

A reestruturação nas relações de trabalho ocorre em um cenário de desigualdade, principalmente no seguinte comparativo: um motorista tradicional contratado via anotação de CTPS tem sua jornada de trabalho regulamentada no artigo 235-C da CLT no qual estipula uma carga horária de 08 horas diárias, como também a remuneração por horas extras e ainda o pagamento das horas relativas ao tempo de espera, essas últimas pagas na proporção de 30\% (trinta por cento) do salário-hora normal (BRASIL, 2018).

Ao revés deste cenário de remuneração e proteção aos limites da jornada, um motorista uberizado contratado via plataforma digital - não tem nenhuma lei que estipule uma jornada máxima de trabalho por ser considerado um motorista parceiro - profissional autônomo. Ou seja, apesar das tarefas realizadas serem idênticas, a depender do modo de contratação do trabalhador haverá um desigual tratamento normativo das condições de trabalho (SOUTO MAIOR, 2021, p. 83).

Para melhor compreensão do tema, o relato empírico a seguir demonstra a condição de trabalho e vida uberizada. O bolsão Pulmman assim conhecido pelos motoristas GRU, que nos remete à reportagem da Folha de São Paulo (MACHADO, 2017), fora interditado algumas vezes pela Polícia Federal, e hoje é apenas um terreno baldio. Apesar do terreno ainda existir não há motivos mais para ficar por lá, porque pelo novo sistema estabelecido pela empresa só é chamado quem está no bolsão oficial da Uber.

$\mathrm{Na}$ atualidade, a Uber possui uma área, dentro do aeroporto de Guarulhos, exclusiva para motoristas parceiros e, que se atenderem aos critérios descritos no site da empresa, terão acesso a um local confortável, com banheiros, água, café, vending machines, e apropriado para estacionar os carros e aguardarem a próxima viagem. Agora, também existem locais de encontro definidos dentro de cada terminal que devem facilitar a encontrar o passageiro. As viagens que forem iniciadas no Aeroporto de Guarulhos incluem uma cobrança extra aos usuários no valor de R \$ 4,50 que será repassada integralmente ao Aeroporto de Guarulhos (UBER, 2021).

A área de espera do motorista possui vagas limitadas e terá capacidade para até 230 motoristas. Para ter acesso ao local, ao motorista é solicitado a mostrar aplicativo que deve indicar na fila no canto superior esquerdo. Só poderão entrar no local motoristas que atenderem esse requisito. Ficar estacionado no entorno da área exclusiva da Uber está em desacordo com as regras do Aeroporto e pode acarretar em multas para o parceiro. Se no aplicativo estiver a mensagem de fila cheia é um indicativo de que o número de motoristas no local está elevado e recomenda-se e que o motorista não deve esperar no aeroporto. Na entrada do bolsão deve-se mostrar o aplicativo com a mensagem de na fila e será liberado para entrar. Se o aplicativo mostrar fila cheia não poderá entrar no local (UBER, 2021). A empresa que faz todo esse controle de acesso ao local. Luan, 38, ensino médio, se diz uber garulhos das antigas, desde o tempo do bolsão atrás do hotel Pullman. Nossa entrevista só se tornou possível porque foi realizada por meio de uma conferência online, utilizando o Skype, enquanto Luan está na espera dentro do bolsão de Guarulhos:

V.V.C - Agora você tem água, café e banheiro?

Luan - Isso sim. Mas precisa de comida de verdade que é proibido vender lá dentro, então eu trago marmita de casa

V.V.C — Que posição você tá na fila agora?

Luan- 180. Eu tava fazendo uma live e o pessoal apostou que eu saio daqui as 9 da manhã. 
V.V.C — Mas são nove da noite!

Luan—é exagero do pessoal, eu devo sair daqui umas três da madrugada.

V.V.C - Eu li no site oficial que o tempo de permanência máximo no bolsão é 5 horas?!

Luan - Ah, as vezes a gente fica menos, as vezes mais. Chega a esperar umas sete horas. Depende. A gente vai sendo jogado pra trás por causa das prioridades.

V.V.C - que prioridade é essa?

Luan — quando chega alguém trazendo um passageiro, ele tem 10 minutos na fila da prioridade pra sair do aeroporto com passageiro também. Nisso a gente da fila normal vai ficando pra trás, por isso demora.

V.V.C - Mas compensa? Ficar esperando tanto tempo por uma corrida?

Luan — Não!

V.V.C - Então por que você vai todo dia?

Luan - Porque eu sou um uber de guarulhos meus parceiros da resenha estão aqui. Nós ficamos na resenha na madrugada. (Luan, 04 de agosto de 2018)

O excerto acima traz um aspecto importante, trata-se do ethos do trabalho associado a um tipo ideal de trabalhador, qual seja aquele integralmente disponível ${ }^{5}$ para o trabalho, a conformação do trabalhador just in time $^{6}$, o trabalhador por demanda (FACHIN, 2020).

Neste sentido, observa-se uma imposição de prontidão, uma situação de permanência indefinida à inteira disposição da plataforma digital sem que esse tempo seja considerado trabalho efetivo. Nesta configuração laboral, caso o motorista uberizado passe todas as horas do dia neste tempo de espera ${ }^{7}$ nada lhe será remunerado. O período em que o uberizado fica aguardando sua convocação durante sua jornada é um tempo invisibilizado e não pago.

Desde os tempos de bolsões informais, esses motoristas vivenciam um caso muito similar ao sistema de contrato de zero hora, no qual o trabalhador não tem jornada fixa, mas ele tem que ficar à disposição dos chamados. Se em um determinado dia ele não recebe nenhum chamado, ele não tem trabalho. No fim, no período de uma semana ele pode ter recebido, por exemplo, apenas três chamadas de uma hora cada, ele receberá, portanto, o valor de três horas semanais. Em uma semana ele esteve 168 horas disponível, mas só recebeu pelas horas que efetivamente trabalhou (ANTUNES, 2016).

Portanto, o conceito de trabalho efetivo é definido unilateralmente pela própria plataforma digital, que no caso é tão somente o tempo de transporte do passageiro. O tempo de deslocamento até ele, não é computado para remuneração, tampouco o tempo necessário para abastecimento e limpeza do veículo. A precisão fornecida pelo código do aplicativo elimina, para a empresa, a necessidade de remunerar um trabalhador pelo fato de estar à sua disposição imediata, limitando a remuneração apenas aos momentos que a Uber entender como de efetivo labor. A disposição organizacional confronta à disposição legal, onde - no artigo $4^{\circ} \mathrm{da}$ CLT - estabelece que o período em que o empregado está à disposição do empregador, aguardando ou executando ordens, é considerado tempo de trabalho efetivo (VIDIGAL, 2020). 
A despeito da possibilidade de controle, ela não é feita, verificando-se a eliminação da mediação da jornada. O movimento de flexibilização joga a favor do capital e não do trabalho. A realidade da atividade dos motoristas nos mostrou que trabalham mais de 12 horas por dia. Dessa forma, Bruno fica 15 horas dentro do carro:

Bruno - Enquanto fico esperando passageiro fico estudando dentro do carro. Não acho que alguém queira ser motorista pra sempre.

V.V.C - Você estuda dentro do carro?

Bruno - Em 15 horas? Eu moro dentro do carro. Estudo ${ }^{8}$, tomo café, almoço, janto, durmo, (pausa) faço tudo mesmo... só usar o banheiro que não dá. (Bruno, 10 de agosto de 2018)

O entrevistado Bruno, por exemplo, não é remunerado pelas 15 horas que seu aplicativo ficou ligado e ele estava dentro do carro, aguardando chamadas. Há outros elementos a serem explorados nesse excerto, quando Bruno diz que mora e faz tudo dentro do carro, em um regime que nem de sobre aviso ${ }^{9}$ é, é de prontidão. ${ }^{10}$ Esses regimes elaborados pelo legislador pensando nos ferroviários em 1966, em ambos o trabalhador estaria aguardando ser chamado. $\mathrm{O}$ traço distintivo entre eles é que no primeiro o trabalhador aguarda em casa, no segundo aguarda nas estradas da ferrovia. O legislador por compreender a espera fora de casa mais desgastante, a limitou em número menor de horas, com relação aquele que aguarda em casa. Bem como estipulou compensação remuneratória maior à situação mais penosa. No caso do trabalhador da Uber o regime é de prontidão, mas as suas vantagens não. Não há limitação temporal do máximo de 12 horas e não há remuneração na espera dentro do carro (VIDIGAL, 2020).

E como destaca Dal Rosso, a exploração do trabalho, na modernidade, passa a ser cada vez mais intensa: "O tempo livre, o tempo de não trabalho, passa a ser engolido pelo trabalho. A tecnologia que poupa trabalho está falhando em liberar aqueles que trabalham" (DAL ROSSO, 2008, p. 71).

As jornadas relatadas por 17 dos 22 entrevistados passam, invariavelmente, de 8 horas diárias. Os entrevistados afirmaram ter jornadas de trabalho que variam entre 45 a 86 horas por semana, ultrapassando o teto estabelecido das 44 horas semanais - conforme artigo $7^{\circ}$, XIII, da Constituição Federal ${ }^{11}$. Portanto, o modelo padrão de jornada brasileiro de 08 horas diárias e 44 horas semanais perfazendo 220 horas mensais, paulatinamente é despadronizado nas últimas décadas em razão das novas tecnologias da informação e comunicação.

\section{Direitos e garantias em espera: a produção legislativa sobre os uberizados}

A emergência dos uberizados trouxe consigo uma nova dinâmica da noção de informalidade, uma escolha política criada para esconder a relação pessoal e subordinada trabalhista existente com a empresa controladora da plataforma digital (CARELLI, 2021).

Os traços de assalariamento no capitalismo de plataforma têm sido objeto de inúmeras decisões judicias em todo o mundo. A jurisprudência trabalhista nacional enfrenta dificuldades para classificar tais figuras sociais. Os dados estatísticos revelam uma propensão da Justiça do Trabalho no sentenciamento a favor das plataformas digitais, ou seja, ao não reconhecimento do vínculo empregatício (OLIVON, 2020).

Existe ainda uma produção de vários projetos de leis na tentativa de impor limites nas condições de trabalho dos uberizados. A espera por um marco regulatório protecionista cria a tendência de considerá-los como autônomos - a autocomercialização do EU S/A (ANDRADE, 2012).

As incipientes tentativas de regulação em relação às plataformas digitais de trabalho reatualizam o Código Negro (Code Noir) que fora um decreto editado pelo Rei Luís XIV no ano de 1685, cujo documento legislativo apenas legitimou a condição de escravidão. A evidência dessa assertiva é observada, verbi gratia, no Projeto de Lei no 3748/2020 de autoria da Deputada Tabata Amaral (PDT-SP), em que propõe um novo regramento de direitos aos trabalhadores de plataforma digital, concedendo apenas a garantia de pagamento do 
salário mínimo/hora na exata medida da sua produção, excluindo o conceito de tempo à disposição (artigo $4^{\circ}$ da CLT) (BRASIL, 2020). O projeto de lei em questão- dentre outros ${ }^{12}$ - precariza e legaliza uma subespécie de trabalhador, abaixo do patamar mínimo civilizatório determinado pela CF/1988 e pela CLT. Ou seja,

[...] guardadas as devidas proporções e momentos históricos, o projeto de lei proposto pela Deputada Tabata Amaral, que propõe regulamentar o trabalho sob demanda realizado por meio de plataformas digitais, pode ser entendido como uma espécie de Código Negro do Século XXI. O projeto parte de uma premissa equivocada que é garantir aos trabalhadores a fruição de uma liberdade impossível de se realizar (CARELLI, 2020, p. 02).

Nesse aspecto legislativo, é importante assinalar um pequeno avanço normativo, no Distrito Federal, onde foi aprovada a Lei $\mathrm{n}^{\circ} 6.677 / 2020$, de autoria do deputado e assistente social Fábio Felix (PSOL). A norma garante cria pontos físicos de apoio ${ }^{13}$ para trabalhadores de aplicativos, trazendo uma previsão legal para garantir algum conforto a quem espera às chamadas (DISTRITO FEDERAL, 2020).

A despeito desse avanço normativo protetivo, a atual conjuntura sinaliza uma produção legislativa de exclusão aos direitos fundamentais trabalhistas, no embate de narrativas contraditórias de autonomia e subordinação, numa verdadeira disputa de projetos de classe. Enquanto o judiciário não unifica sua jurisprudência e o legislativo não aprova/sanciona nenhuma lei acerca do tema, os uberizados continuam à espera de direitos trabalhistas e sociais básicos, além de estarem à espera dos chamados. Nesse sentido, a seção a seguir tem como objetivo problematizar a condição de trabalho e vida de quem espera.

\section{A saúde não pode esperar: o sofrimento psíquico no trabalho uberizado}

A imposição de um limite e marcos regulatórios na jornada foi e é preciso, pois existe o impulso do capitalismo de plataforma em se apropriar do trabalho na inteireza das 24 horas diárias. E diante da atual ausência de medidas e controle, surge a presente problemática, no sentido de que a não fruição, reiterada, do descanso semanal, intervalos, férias, acarreta danos à saúde. Nietzsche (1844-1900), ainda na sua época, já chamava a atenção para o fato de que a vida humana finda numa hiperatividade mortal se dela for expulso todo elemento contemplativo: "por falta de repouso, nossa civilização caminha para uma nova barbárie" (NIETZSCHE, 2018, p. 37).

As discussões que buscam relacionar trabalho e saúde/doença possuem já uma longa história em diversas áreas do conhecimento. A respeito do tema, Marx ao narrar as jornadas extenuantes ocorridas nas primeiras revoluções industriais, relatou a morte por exaustão ${ }^{14}$ da inglesa Mary Anne Walkley em 1863 após trabalhar initerruptamente 30 horas em uma oficina que fabricava vestidos; este sobretrabalho fatal demonstra que "[...] o capital não tem, por isso, a mínima consideração pela saúde e duração de vida do trabalhador, a menos que seja forçado pela sociedade a ter essa condição" (MARX, 2013, p. 432).

Outro marco nas pesquisas relacionados à temática veio com os estudos realizados por Christophe Dejours (1999) e sua equipe, no Laboratório de Psychologie du Travail et de l'Action, do Conservatoire Nationaldes Arts et Metiers (CNAM), em Paris. Cristophe Dejours (1999) demonstra que a depressão, suicídios e uma série de adoecimentos psíquicos também são parte das configurações que a exploração do trabalho tem neste século.

Esta pesquisa contribuirá para esse debate, na medida em que o trabalho do motorista de Uber é compreendido como uma atividade naturalmente estressante (trânsito), as jornadas são extensas e são submetidos a intensos ritmos de trabalho. As longas jornadas extenuantes, típicas da referida precarização das relações de trabalho, podem causar danos que não se restringem à saúde física e mental dos entrevistados. Um acidente de trânsito, por exemplo, pode impossibilitar o motorista de dirigir e auferir renda.

Para além, é necessário reconhecer que a uberização atualizou o conteúdo de adoecimento do trabalho. Durante a jornada dos uberizados existe uma aguda expectativa pelos chamados. Nos grandes intervalos em que não se descansa e nem efetivamente existe trabalho remunerado há uma elevação da carga mental (HAICAULT, 1984). Em outras palavras, os tempos de espera, além de não serem remunerados, são nocivos para a saúde mental dos uberizados, em razão da ansiedade gerada pela obrigação do cumprimento das metas ${ }^{15}$.

A propósito, Patrícia, 45 anos, ensino médio, e seu esposo Miguel, 47 anos, ensino médio, relataram que trabalhavam por 15 horas como motoristas de Uber, principalmente no período noturno, e consequentemente, 
acabavam dormindo apenas três-quatro horas por dia. Ambos ingressaram na Uber com a intenção de aumentar a fonte de renda, eram autônomos, ela "vendia lingerie pela cidade" e ele fazia "bicos como mecânico". A realização de duas cirurgias cardiovasculares do marido e a sua saúde fragilizada, a fizeram repensar sua rotina de trabalho, antes marcada por uma jornada exaustiva.

Patrícia- meu esposo infartou por conta de ter que virar noites trabalhando e tendo que ficar a base de energéticos, já passou por dois procedimentos cardíacos e hoje não pode mais trabalhar tantas horas.

V.V.C- Os médicos alegaram ser devido ao trabalho, ao energético?

Patrícia- Na verdade não culpam o energético, e sim as condições de trabalho dormindo apenas 2 a 4 horas por noite. É trabalhando sobre stress excessivo.

V.V.C- Eles falaram que faz mal e vocês trabalham 15 horas por dia?

Patrícia - Sim pra poder ter uma renda que suprisse a nossa necessidade.

V.V.C- Mas se você trabalhar oito horas por dia na Uber não basta?

Patrícia- Jamais. (Patrícia, 2 de agosto de 2018)

No caso desses motoristas, o excesso de trabalho e desempenho agudiza-se numa autoexploração que caminha de mãos dadas com o sentimento de liberdade. No entanto, esse sentimento de liberdade pode ser destrutivo. O sujeito do regime neoliberal perece com o imperativo da otimização pessoal. Pontua Byung-Chul Han (2017, p. 100-101) que "o sujeito do desempenho explora a si próprio até consumir-se completamente (burnout)". A síndrome de Burnout pode ser descrita como:

A síndrome da estafa profissional, também denominada síndrome de burnout, foi descrita pela primeira vez pelo psicólogo H.J. Freudenberger, no ano de 1974, para descrever um sentimento de fracasso e exaustão causado por um excessivo desgaste de energia, forças e recursos [...]. Os primeiros sentimentos negativos são direcionados aos desencadeantes do processo, ou seja, clientes e colegas de trabalho, posteriormente atingindo amigos e familiares e, por último, o próprio profissional (SOARES; CUNHA, 2007, p. 505-506).

Entrar em burnout significa chegar ao limite da resistência física ou emocional (CARVALHO, 2003). Conforme Dorea (2008), seria um retorno emocional das situações de estresse, vivenciadas através das relações intensas no trabalho, como aqueles que são submetidos a baixos-salários, assédios, competição no ambiente de trabalho e à falta de reconhecimento. Segundo Jbeili (2008, p. 10) os sintomas físicos podem se manifestar das seguintes formas "exaustão, fadiga, dores de cabeça, dores generalizadas, transtornos no aparelho digestivo, alteração do sono e disfunções sexuais". Os sintomas psicológicos mais comuns são "quadro depressivo, irritabilidade, ansiedade inflexibilidade, perda de interesse, descrédito (sistema e pessoas)".

O objetivo que justifica a existência das pausas reais no trabalho, aponta para a direção de que suas concessões significam não só o respeito aos direitos sociais previstos constitucionalmente, como também oportunizar um tempo para que o trabalhador recarregue suas energias, que a mente não se sobrecarregue e para que se exerça o direito ao lazer e a desconexão. Cataldi (2011) esclarece que essas "normas têm como fundamento três aspectos importantes: fatores biológicos, sociais e econômicos. É indiscutível o fato de que o excesso de trabalho causa fadigas física e mental, estresse e cansaço ao trabalhador".

$\mathrm{Na}$ vigente pandemia do COVID-19, a situação acima citada acentuou a sobrecarga mental desses trabalhadores uberizados. Em recente estudo (ABÍLIO et al, 2020), aproximadamente 84\% dos entrevistados 
disseram sentir medo de serem contaminados durante a prestação dos serviços, como também descreveram situações que envolvem forte grau de tensão e de ansiedade.

Desse cenário, conclui-se que o risco psicólogo é inerente ao trabalho uberizado. Sendo possível verificar a longo prazo um quadro de depressão, síndrome de pânico, burnout e até mesmo suicídio dos trabalhadores, enquanto ausentes as tutelas protetivas.

\section{Considerações finais}

O modo de espera introduz na análise da relação entre a organização do trabalho uberizado e a saúde do trabalhador uma situação nova, comparada aos arranjos de trabalho tradicionais fordistas. Há um conteúdo no tempo da jornada, que não é o conteúdo de tempo do deslocamento ao trabalho, do descanso ou da execução efetiva de tarefa. O conteúdo do tempo do modo de espera, um tempo de trabalho não pago, revela implicações em termos de saúde do trabalhador, ao não se desligar psiquicamente do trabalho. Um alto grau de ansiedade é gerado pela espera de um chamado de trabalho remunerado que pode significar sua subsistência material e sobrevivência.

As linhas pretéritas podem parecer desanimadoras, mas os uberizados devem, doravante, esperançar no sentido posto pelo educador Paulo Freire, como um horizonte que depende da luta de classes. Movimentos de organização coletiva, a exemplo do que ocorreu no \#BrequeApp ${ }^{16}$, são indícios de que a emancipação da força de trabalho ao capital é possível, numa nova morfologia de resistência que se desenha.

Nesse sentido, verifica-se também que o tempo de espera pode ser algo positivo, quando ela é realizada em locais em que os trabalhadores se encontram, e assim têm tempo de discutir os problemas, compartilhar as insatisfações, debater as pautas de reinvindicações, potencializando uma organização coletiva. Esse tempo de espera serve à construção coletiva da mobilização, na espera por condições de trabalho e vida melhores.

\section{Referências}

ABÍLIO, Ludmila Costhek et al. Relatório técnico das condições de trabalho em empresas de plataforma digital: os entregadores por aplicativo durante a Covid-19. São Paulo: REMIR, 2020.

ANDRADE, Everaldo Gaspar Lopes de. O direito do trabalho na filosofia e na teoria social crítica: os sentidos do trabalho subordinado na cultura e no poder das organizações. Revista TST, Brasília, vol. 78, no 3, jul/set 2012, p. 37-63.

ANTUNES, Ricardo. Adeus ao trabalho?: ensaio sobre as metamorfoses e a centralidade do mundo do trabalho. São Paulo: Cortez, 2016. BRASIL. Câmara dos Deputados. Projeto de lei 3748/2020. Institui e dispõe sobre o regime de trabalho sob demanda. Brasília, DF, 10 jul. 2020. Disponível em: https://www.camara.leg.br/propostas-legislativas/2257468. Acesso em: 8 set. 2021.

BRASIL. Decreto-lei n ${ }^{\circ} 5.452$, de $1^{\circ}$ de maio de 1943. Aprova a Consolidação das Leis do Trabalho. Brasília, DF: Presidência da República, [2021]. Disponível em: http://www.planalto.gov.br/ccivil_03/decreto-lei/del5452.htm. Acesso em: 8 set. 2021.

BRASIL. Lei no 13.103 , de 2 de março de 2015. Dispõe sobre o exercício da profissão de motorista; altera a Consolidação das Leis do Trabalho - CLT, aprovada pelo Decreto-Lei $n^{\circ} 5.452$, de $1^{\circ}$ de maio de 1943, e as Leis no 9.503, de 23 de setembro de 1997 - Código de Trânsito Brasileiro, e 11.442, de 5 de janeiro de 2007 (empresas e transportadores autônomos de carga), para disciplinar a jornada de trabalho e o tempo de direção do motorista profissional; altera a Lei n ${ }^{\circ} 7.408$, de 25 de novembro de 1985; revoga dispositivos da Lei $n^{\circ}$ 12.619, de 30 de abril de 2012; e dá outras providências. Brasília: DF, Presidência da República, [2018]. Disponível em: http:// www.planalto.gov.br/ccivil_03/_ato2015-2018/2015/lei/113103.htm. Acesso em: 8 set. 2021.

BRASIL. Supremo Tribunal Federal. Ação Direta de Inconstitucionalidade n 5.322/DF. Relator: Ministro Teori Zavascki, Brasília, 2016. Disponível em: http://portal.stf.jus.br/processos/detalhe.asp?incidente=4778925. Acesso em: 29 jun. 2021.

CARDOSO, Ana Claudia Moreira; ARTUR, Karen; OLIVEIRA, Murilo Carvalho Sampaio. O trabalho nas plataformas digitais: narrativas contrapostas de autonomia, subordinação, liberdade e dependência. Revista Valore, v. 5, p. 206-230, 2020.

CARELLI, Rodrigo de Lacerda. O projeto de regulamentação do trabalho em plataformas: um novo Código Negro? Jornal GGN, Governador Valadares, 07 ago. 2020. Disponível em: https://jornalggn.com.br/cidadania/o-projeto-de-regulamentacao-do-trabalhoem-plataformas-um-novo-codigo-negro-por-rodrigo-de-lacerda-carelli/. Acesso em 21 jun. 2021.

CARELLI, Rodrigo de Lacerda. O enviesamento de conceitos básicos sobre a uberização. Jornal GGN, Governador Valadares, 04 jun. 2021. Disponível em: https://jornalggn.com.br/destaque-secundario/o-enviesamento-de-conceitos-basicos-sobre-a-uberizacaopor-rodrigo-de-lacerda-carelli/. Acesso em: 21 jun. 2021. 
CARVALHO, Fatima Araujo de. O mal-estar docente: das chamas devastadoras (burnout) às flamas da esperança-ação (resiliência). Dissertação (Mestrado em Psicologia da Educação) - Pontifícia Universidade Católica de São Paulo, São Paulo, 2003.

CASTRO, V. V. As ilusões da uberização: um estudo à luz da experiência de motoristas Uber. Dissertação (Mestrado em Sociologia) - Universidade Estadual de Campinas, Campinas, 2020.

CATALDI, Maria José Giannella. Stress no Meio Ambiente de Trabalho. São Paulo: LTR, 2011.

DAL ROSSO, Sadi. Mais trabalho!: a intensificação do labor na sociedade contemporânea. São Paulo: Boitempo, 2008.

DEJOURS, C. A banalização da injustiça social. Rio de Janeiro, Brasil: Editora FGV, 1999.

DISTRITO FEDERAL. Lei n 6677 de 22/09/2020. Dispõe sobre os pontos de apoio para trabalhadores de aplicativos de entrega e de transporte individual privado de passageiros nas regiões administrativas do Distrito Federal. Distrito Federal, set. 2020. Disponível em: https://www.legisweb.com.br/legislacao/?id=401717. Acesso em: 8 set. 2021.

DOREA, M. P. T. Síndrome de Burnout: o stress em estudantes de medicina. Rio de Janeiro; Ed. Publit, 2008.

EU, Daniel Blake. Direção: Ken Loach. Produção de Rebecca O’Brien. Reino Unido: Sixteen Films, 2016. 1 DVD.

FACHIN, P. Breque dos Apps é um freio coletivo na uberização e na degradação e exploração do trabalho. [Entrevista cedida a] Patricia Fachin. Instituto Humanitas Unisinos, São Leopoldo, 5 ago. 2020. Disponível em: http://www.ihu.unisinos.br/159-noticias/ entrevistas/601524-breque-dos-apps-e-um-freio-coletivo-na-uberizacao-e-na-degradacao-e-exploracao-do-trabalho-entrevista-especialcom-ludmila-abilio. Acesso em: 20 ago. 2020.

HAICAULT, Monique. La gestion ordinaire de la vie en deux. Sociologie du Travail, Elsevier Masson, ano 26, n. 3, p. 268-277, 1984. HAN, Byung-Chul. A sociedade do cansaço. Rio de Janeiro: Petrópolis, Vozes, 2017.

JBEILI, C. Síndrome de Burnout: Identificação, tratamento e prevenção. Ed. CDU, 2008.

MACHADO, L. Por corrida cara, motorista do Uber "acampa" por 12h perto de aeroporto. Folha de São Paulo, São Paulo, 9 fev. 2017. Disponível em: http://www1 folha.uol.com.br/cotidiano/2017/02/1857136-por-corrida-cara-motorista-do-uber-acampa-por-12h-perto-de-aeroporto.shtml/. Acesso em: 9 fev. 2017.

MARX, Karl. O Capital: livro 1, o processo de produção do capital. São Paulo: Boitempo, 2013. v.1 t. 1.

NIETZSCHE, Friedrich. Humano, Demasiano Humano. Santos: Lafonte, 2018.

OHNO, Taiichi. O sistema toyota de produção: além da produção em larga escala. Porto Alegre, Bookman, 1997.

OLIVON, Beatriz. Placar na Justiça do Trabalho é favorável às empresas de aplicativo. Valor Globo, São Paulo, 24 jul. 2020. Disponível em: https://valor.globo.com/legislacao/noticia/2020/07/24/placar-na-justica-do-trabalho-e-favoravel-as-empresas-de-aplicativo.ghtml. Acesso em: 8 set. 2021.

SENNETT, Richard. A corrosão do caráter: consequências pessoas do trabalho no novo capitalismo. Rio de Janeiro: Record, 2003.

SOARES, Hugo Leonardo Rodrigues; CUNHA, Carlos Eduardo Camargo. A síndrome do "burn-out": sofrimento psíquico nos profissionais de saúde. Revista do Departamento de Psicologia, Niterói, v. 19, p. 505-506, 2007.

SOUTO MAIOR, Nívea Maria Santos. Os infoproletariados. Leme: Mizuno, 2021.

UBER. Aeroporto de Guarulhos (GRU). Uber Brasil, [2021]. Disponível em: https://www.uber.com/br/pt-br/drive/sao-paulo/airports/ guarulhos-airport/. Acesso em: 8 set. 2021.

UBER. Descubra as categorias de Uber e como podem te ajudar no dia a dia. Uber Brasil, 18 set. 2018. Disponível em: https://www. uber.com/pt-BR/blog/categorias-da-uber/. Acesso em: 8 set. 2021.

VIDIGAL, V. Delivery viral: entre a virtualidade do pedido e a concretude da entrega. In: CASTRO, B. (Org.). Covid-19 e Sociedade: ensaios sobre a experiência social da pandemia. Campinas: IFCH, 2020. p. 278-294.

VOCÊ não estava aqui. Direção: Ken Loach. Reino Unido: Telecine Cult, 2020. 1 DVD.

\section{Notas}

1 A conhecida frase A arte imita a vida é atribuída ao filósofo grego Aristóteles (Estagira, 384 a.C. — Atenas, 322 a.C.). Porém, a frase é uma livre adaptação da frase original "A arte imita a natureza" publicada em Física, Livro II. No texto, Aristóteles trabalha com os conceitos de arte (techné), imitação (mímesis) e natureza (physis). Não se trata, portanto, da arte como poiesis e da vida como práxis. Em outro trabalho (Poética), Aristóteles escreve a respeito da arte no sentido que é usada na frase adaptada. Nesse texto, fala-se especificamente da poesia - que, na Antiguidade, tinha um alcance bem maior do que hoje. Aristóteles deixa claro que a poesia, nesse sentido mais lato, é imitação.

2 O neologismo Uberização não se resume ao modelo de atividades exercidas pela Uber, mas a nomenclatura sinaliza que o modus operandi daquela empresa ganhou notoriedade e foi amplamente difundido no mercado de trabalho via plataformas digitais. 
3 Importa registrar ainda que a relevância deste objeto se cinge na ampliação no setor de serviços de entrega e transporte de passageiros no Brasil, como também no aumento de aproximadamente $40 \%$ na quantidade atual de motoristas intermediados por plataformas digitais, em referência a 1,3 milhão em 2016 para 2,0 milhões em 2020 (CARDOSO; ARTUR; OLIVEIRA, 2020, p. 212).

4 A principal e mais usada opção da Uber, o UberX oferece viagens com preços acessíveis em carros compactos de quatro portas e ar-condicionado. Presente em todas as cidades brasileiras onde a Uber opera. (UBER, 2018)

5 Richard Sennett (2003) já se referia à ideia de disponibilidade integral em A corrosão do caráter, ao relatar a história de Rico, um trabalhador que atuava em contrato flexível, fazendo contraposição ao taylorista-fordista.

6 Pode ser traduzido livremente como na hora certa ou no momento exato. Concebido no Japão, em oposição ao Just-in-Case fordista, e que tem se difundido pelo mundo nas últimas décadas, juntamente com outros aspectos do Toyotismo. "Just-in-time significa que, em um processo de fluxo, as partes corretas necessárias à montagem alcançam a linha de montagem no momento em que são necessárias e somente na quantidade necessária. Uma empresa que estabeleça esse fluxo integralmente pode chegar ao estoque zero" (OHNO, 1997, p. 26).

7 "Tempo de espera é instituto específico do transporte de cargas, inaugurado pela Lei 12.619/2012, e corresponde ao período em que motoristas permanecem em filas aguardando embarque ou desembarque de cargas, no embarcador ou destinatário ou em postos de fiscalização. Legislações da União Europeia, do Chile e dos Estados Unidos, entre outras, contam com instituto análogo. Na Espanha, por exemplo, há previsão do 'tempo de presença' ('tiempo de presencia'), aquele em que o trabalhador de transportes não presta trabalho efetivo por 'espera, expectativa, serviço de plantão, viagens sem serviço, avarias, refeições em rota ou outras similares'. Ante o significado comumente atribuído ao termo, trabalho 'efetivo' corresponde ao 'que se realiza, que é real e positivo, que funciona de fato, que produz efeitos, que é estável ou permanente'. É indubitável que a atividade de motoristas durante espera de embarque e desembarque e em fiscalizações constitui trabalho realizado em proveito da atividade econômica. [...] Rodrigo Janot Monteiro de Barros - Procurador-Geral da República” (BRASIL, 2016, p. 105-106).

8 Bruno fez ensino médio e agora estuda para ser comissário de bordo.

9 Art. $244[\ldots] \S 2{ }^{\circ}$ Considera-se de sobreaviso o empregado efetivo, que permanecer em sua própria casa, aguardando a qualquer momento o chamado para o serviço. Cada escala de sobreaviso será, no máximo, de vinte e quatro horas, as horas de sobreaviso, para todos os efeitos, serão contadas à razão de 1/3 (um terço) do salário normal (BRASIL, 2021).

10 Art. $244[\ldots] \S 3^{\circ}$ Considera-se de prontidão o empregado que ficar nas dependências da estrada, aguardando ordens. A escala de prontidão será, no máximo, de doze horas. As horas de prontidão serão, para todos os efeitos, contadas à razão de 2/3 (dois terços) do salário-hora normal (BRASIL, 2021).

$\S 4^{\circ}$ Quando, no estabelecimento ou dependência em que se achar o empregado, houver facilidade de alimentação, as doze horas de prontidão, a que se refere o parágrafo anterior, poderão ser contínuas. Quando não existir essa facilidade, depois de seis horas de prontidão, haverá sempre um intervalo de uma hora para cada refeição, que não será, nesse caso, computada como de serviço.

11 O estabelecimento de um limite máximo não determina que a jornada seja fixa nesse limite, ela pode ser flexível para baixo. O que a legislação garante é um patamar mínimo de civilidade que garanta boas condições de trabalho (BRASIL, 2021).

12 No Poder Legislativo, existem dezenas de iniciativas parlamentares que tentam normatizar e introduzir seção específica na CLT para dispor sobre o trabalho realizado via plataforma digital. Os relevantes projetos de lei são mais especificamente: PL 5622/2019 - PL 5622/2019 - PL 6015/2019 - PL 3515/2020 - PL 3538/2020 - PL 3554/2020 - PL 3572/2020 - PL 3577/2020 - PL 3797/2020 - PL 4172/2020 - PL 3748/2020 - PL 3954/2020 - PL 4111/2020 - PL 6423/2019.

13 Em específico, transcreve-se o artigo $2^{\circ}$ da referida lei distrital: “[...] Os pontos de apoio devem contar com: I - sanitários masculinos e femininos; II - chuveiros individuais; III - vestiários; IV - uma sala para apoio e descanso dos trabalhadores, com acesso a internet sem fio e pontos de recarga de celular gratuitos; V - espaço para refeição; VI - espaço para estacionar bicicletas e motocicletas; VII - ponto de espera para veículos de transporte individual privado de passageiros” (DISTRITO FEDERAL, 2020)

14 A morte por exaustão no trabalho é algo bastante inerente aos vários modos de produção, durante o auge do toyotismo foi alcunhada a expressão Karoshi “[...] que se refere à morte súbita no trabalho, provocada pelo ritmo e intensidade, que decorrem da busca incessante do aumento da produtividade" (ANTUNES, 2016, p. 50).

15 As metas são predeterminadas pelo próprio trabalhador que só param de trabalhar quando as atingem. Tais metas estão inseridas num sistema de produtividade denominado gamificação, à semelhança de um jogo de videogame onde são feitas recompensas aos uberizados conforme determinado número de corridas ou entregas ao dia.

16 Trata-se de um novo movimento grevista que aconteceu em julho de 2020, os motofretistas por aplicativo paralisaram suas atividades em todo o País reivindicando melhores condições de trabalho, a exemplo do aumento na remuneração pelas taxas de entrega e do fim dos bloqueios indevidos. 


\section{Viviane Vidigal}

v192482@dac.unicamp.br

Mestra em Sociologia pela Universidade Estadual de Campinas (UNICAMP)

Doutoranda em Sociologia na Universidade Estadual de Campinas (UNICAMP)

\section{UNICAMP}

Rua Cora Coralina, 100, Cidade Universitária.

Campinas - São Paulo - Brasil.

CEP: 13083-896.

\section{Nívea Maria Santos Souto Maior}

nivea.maior@ufpe.br

Mestra em Direito Público pela Universidade Estácio de Sá

Mestra em Serviço Social pela Universidade Estadual da Paraíba (UEPB)

Doutoranda em Direito na Universidade Federal de Pernambuco (UFPE)

Professora no Curso de Graduação em Direito do Centro de Educação Superior Reinaldo Ramos (CESREI)

\section{CESREI Faculdade}

Rua Fernandes Vieira, 1210, Mirante.

Campina Grande - Paraíba - Brasil.

CEP: $58407-490$

\section{Agradecimentos}

Não se aplica.

Agência financiadora

Não se aplica.

Contribuições das autoras

$\mathrm{O}$ artigo foi escrito em coautoria e trata de temática de interesse de ambas autoras. As entrevistas foram realizadas e analisadas por Viviane Vidigal, sendo resultados de sua pesquisa de mestrado. Os demais elementos do texto foram produzidos, por completo, com participação de ambas autoras.

\author{
Aprovação por Comitê de Ética e consentimento para \\ participação \\ As entrevistas foram aprovadas pelo Comitê de Ética em \\ Pesquisa da Universidade Estadual de Campinas, CAAE \\ 78685917.7.0000.5404. Todos os participantes assinaram \\ e receberam cópia do Termo de Consentimento Livre e \\ Esclarecido. \\ Consentimento para publicação \\ Consentimento das autoras. \\ Conflito de interesses \\ Não há conflito de interesses.
}


